\title{
DESAFÍOS PARA PENSAR... LA ENSEÑANZA DE LA FILOSOFÍA
}

Walter Omar Kohan.

Universidad del Estado de Río de Janeiro, Brasil.

\section{Resumen*}

Los problemas que plantea la enseñanza de la filosofía son múltiples, pues supone lo que entendemos por filosofía y por enseñar y aprender filosofía. En este sentido la enseñanza y el aprendizaje se convierten en un problema filosófico, en un reto que da que pensar, tal como ya lo habían entrevisto Sócrates y Platón. El problema se torna aún más complejo cuando nos preguntamos por la significación de enseñar filosofía ante las dificultades y situaciones de los pueblos latinoamericanos.

Palabras clave: enseñanza de la filosofía, docencia en filosofía.

\begin{abstract}
Challenges to think about... the teaching of Philosophy.

The problems posed by the teaching of philosophy are diverse because they involve what we understand by philosophy, and by teaching and learning philosophy. In this way, teaching and learning become a philosophical problem, a challenge to think about, as had already been foreseen by Socrates and Plato. The problem becomes even more complex when we ask ourselves about the significance of teaching philosophy with regards to the difficulties and situations of Latin American people
\end{abstract}

Key Words: teaching of philosophy, teaching in philosophy.

\section{INTRODUCCIÓN}

¿Qué significa enseñar y aprender filosofía? La filosofía tiene que ver con una cierta sensibilidad. Cuando pregunto ¿qué es la filosofía? Lo interroga, por ejemplo, un colega nuestro, italiano, de la Universidad de Napoli, Giuseppe Ferraro, al afirmar que la filosofía es la única forma de saber que tiene un sentimiento en la propia palabra. Philosophía,

\footnotetext{
* Conferencia inaugural del VII Encuentro de Profesores que Enseñan Filosofía, 2008, Universidad Pedagógica y Tecnológica de Colombia, Escuela de Filosofía y Humanidades
} 
aquella vieja etimología griega formada por phílos, que quiere decir amigo, amante, y sophía, que quiere decir saber, o sea, la philosophía tiene dentro de su palabra un sentimiento de amistad, de amor; eso quiere decir que allí está su propia razón o sentido; no hay filosofía sin ese sentimiento, no hay filosofía sin sensibilidad, sin una cierta apertura a los otros y al mundo; algo de esto afirmaba Óscar Pulido en la apertura, al decir que para ir a un encuentro hay que salir del lugar. En educación tenemos esa manía de transformar a los otros, pero se trata de algo distinto: de hacer del encuentro una posibilidad de transformarnos a nosotros mismos.

En el fondo siempre estamos tratando la misma cuestión acerca de qué es la filosofía. En el título de esta conferencia "Desafíos para pensar... la enseñanza de la filosofía" está la palabra "desafíos", y el primer desafío es éste, de darle sentido al título cuando uno se encuentra con otros, cuando los ojos empiezan a ver, cuando la sensibilidad se abre y uno escucha palabras, ve miradas, percibe cuerpos que atienden, que sienten de una manera y que caminan y entonces uno empieza a pensar de verdad en lo que quiere decirle a esas miradas, esos oídos, esos cuerpos y las expectativas de la educación en filosofía.

A éste problema se refiere Platón en La República, cuando habla de la educación de los guardianes; allí afirma que la educación es una clave para introducir la justicia en la polis y que cuanto antes se empiece a formar a los que llegan al mundo, mejor; da mucha importancia a los principios, a los primeros momentos; sobre todo con la infancia, dice Platón, porque cuando un ser nace le parece que está muy moldeable, sumamente plácido, tan sin forma que se le puede dar casi la forma que se quiera. Bueno, ahora estamos en la infancia de este encuentro, está muy maleable, casi sin forma, de modo que la sensación es un poco abismal y exagerada de que ahora le podemos dar al encuentro la forma que más o menos nos plazca, nos apetezca. Y no es fácil cuando se llega de un lugar tan distante y distinto.

En todo caso, estamos en una historia en común y lo que nos reúne es la filosofía; estamos profesores de filosofía, nos las vemos con el enseñar y el aprender, todas palabras que en sí mismas dicen poco, porque se las dicen de muchas maneras. Volvamos a preguntar, entonces, ¿qué es la filosofía? La filosofía es un mundo de filosofías, de relaciones con el saber. Y enseñar y aprender filosofía abren otros tantos mundos. ¿Qué significa enseñar?, ¿qué significa aprender?, ¿qué relación existe entre el enseñar y el aprender filosofía? Cuando alguien aprende filosofía, ¿es porque alguien le ha enseñado?

Consideremos el titulo de este encuentro. Si me permiten, es un poco arrogante, en tanto se propone como un "Encuentro de profesores que enseñan filosofía". A uno le dan ganas de preguntar: ¿cómo saben estos profesores que enseñan filosofía? Porque pareciera que la filosofía no es algo que uno pueda decir que se realiza simplemente por ocupar un espacio institucional o una materia curricular, es decir, el hecho de que uno entre en una escuela y ocupe la carga horaria de filosofía, en un sentido más formal, no significa que enseña filosofía. Pareciera que enseñar filosofía exigiría algunas condiciones, al menos, en relación 
con la propia concepción de la filosofía y de lo que supone su aprendizaje, algo de lo que tal vez nunca podremos estar del todo seguros.

De modo que muchos profesores pueden creer que enseñan filosofía, y enseñar algo diferente o no dejar aprender filosofía. En todo caso, no estaría mal si la próxima edición de este encuentro se llama "Encuentro de profesores que creen que enseñan filosofía" o "que no creen que enseñan filosofía" o "que creen que no enseñan filosofía". No estaría mal que profesores con esas convicciones se encuentren en la próxima edición. Y tampoco estaría mal que participen de ese encuentro estudiantes "que sostienen que aprenden filosofía" o "que no sostienen que aprenden filosofía" o "que sostienen que no aprenden filosofía", por razones semejantes. De modo que, de un lado, no basta con tener un diploma, entrar todos los días a una institución, recibir un salario, que a uno lo llamen profesor, tener un currículo sustantivo relacionado con esta disciplina; del otro lado, no es suficiente con tener buenas notas en las calificaciones, saberse muchos nombres de filósofos...

A la vez, no es tan clara la relación entre enseñar y aprender filosofía. En pedagogía, durante bastante tiempo, se abusaba de los conectivos y se hablaba mucho del proceso de "enseñanza-aprendizaje". Bueno, creo que no es tan evidente que siempre que alguien aprende es porque otro le enseñó; tampoco, que todas las enseñanzas generan aprendizajes. ¿Quién sabe? ¿Quién puede asegurar que un estudiante que aprende, aprende lo que un profesor le enseñó? ¿Cómo negar que un estudiante puede aprender contra lo que un profesor pretende enseñarle?

En fin, vemos que no es tan fácil esto de enseñar y aprender; se trata de una situación problemática, en el sentido de que es un problema que merece ser pensado. Entonces, en cierto modo estamos dentro de la propia filosofía. En efecto, la enseñanza de la filosofía es un problema filosófico. Como decía antes Óscar Pulido, la filosofía tiene mucho que ver con poner problemas, antes que con resolverlos, con hacer notar que lo que parece simple no lo es tanto.

\section{La enseñanza de la filosofía como problema filosófico}

De modo que parece que hemos empezado bien, estamos en un inicio promisor, en el sentido de que estamos en un campo problemático: la enseñanza de la filosofía se constituye como un problema filosófico. Digo que es un buen inicio porque hay una tendencia fuerte a reducir el problema de la enseñanza de la filosofía a un problema técnico, didáctico, instrumental. Y en ese movimiento se lo desplaza fuera de la propia filosofía. A la vez, puede ser un buen inicio si nos permite a los profesores de filosofía, a los que decimos que enseñamos filosofía, o creemos hacerlo, problematizarnos a nosotros mismos, problematizar lo que hacemos en nombre de la enseñanza de la filosofía y cómo lo hacemos; de modo que estaría muy satisfecho si en este inicio podríamos ver algunos problemas donde no vemos, o disponer algunas preguntas donde solo teníamos respuestas. 
Creo que eso es lo más importante de lo que nos convoca un encuentro alrededor de la enseñanza de la filosofía, para que nos preguntemos una vez más qué es la filosofía, qué relación tenemos con ella, qué pensamos acerca del enseñar y del aprender, para qué enseñamos, para qué aprendemos y para qué ponemos la filosofía en medio de ese par; porque decimos que enseñamos filosofía, y no otra cosa, o afirmamos que formamos filosóficamente.

Ya Deleuze, filósofo francés contemporáneo, en su libro Diferencia y repetición ${ }^{1}$ relacionaba fuertemente estas dos palabras y concebía el pensar como una especie de encuentro. Decíamos antes que la filosofía es en cierto modo una forma de atención, de estar atentos, de abrir la sensibilidad, de atender lo que luce sin importancia, lo que parece insignificante, lo que resulta obvio o natural, para eso hay que disponerse de una cierta manera, pero tampoco se puede anticipar o preconfigurar, como si dijéramos "bueno, vamos a encontrar este o aquel problema"... no se puede anticipar, forzar..., así nadie encuentra nada; no se puede programar ni forzar nadie a encontrar nada...; a veces queremos poder encontrar algo, tanto que nos alejamos de esa posibilidad; o estamos empecinados en reconocer algo que ya sabemos y, de repente, cuando estamos pensando en otra cosa, nos encontramos con algo que no habíamos pensando; de modo que es compleja esa disposición para el encuentro; importa abrir la sensibilidad, abrirse a lo que no pensamos y eso es bastante difícil de enseñar y de aprender. En todo caso, creo que la apertura principal de la disposición es de la sensibilidad: si uno piensa que ya sabe, que siempre los otros tienen que encontrar las maravillas que uno piensa, pues seguro que de allí uno no se va a mover; y pensar, encontrar, es de alguna manera salir del lugar del pensamiento en que uno está para pensar de otra manera.

Por otro lado, desde Sócrates la filosofía no sólo tiene que ver con el pensamiento, sino con la vida. Entonces, de alguna manera, enseñar filosofía es enseñar a vivir; sé que esto suena muy pretencioso; no se trata de decirles a los otros cómo tienen que vivir, pero sí que los otros aprenden a mirar su vida, a problematizarla y eventualmente a vivir de otra manera. La filosofía puede tornar la vida más interesante, más compleja, más digna de ser vivida. Volveremos sobre este punto.

Bueno, ¿ven que no es poca cosa lo que puede surgir de un encuentro de filosofía? Y curiosamente, también desde Sócrates, la filosofía está tan ligada al saber cuanto al no saber. Desde entonces no sabemos qué sabe la filosofía, a no ser una cierta relación con el saber. Pero no hay un saber filosófico consagrado, fijo, a no ser la pluralidad de saberes consagrados por la tradición en tanto pluralidad, controversia, es decir, no es posible siquiera saber qué es la filosofía; conviven innumerables concepciones de filosofía, casi tantas como filósofos. Como decía Nietzsche, la filosofía no nace del asombro, sino del error y del horror. Creo que de esto último "sabemos" bastante los que vivimos en esta parte del mundo, y justamente en este contexto creo que tiene mucho menos sentido la

\footnotetext{
${ }^{1}$ DELEUZE, G. Diferencia y repetición. Buenos Aires: Amorrortu, 2002
} 
filosofía si se muestra como un saber fijo, consolidado, de reconocimiento, que si se pone a disposición para pensar el horror en el que vivimos y de qué otra manera podríamos vivir.

\section{1 ¿Qué es ser profesor de filosofía?}

De modo que la filosofía no se puede definir, no en el sentido de que no sea posible definir, sino en el de que toda definición que pretende abarcarla le quita fuerza al trabajo del pensamiento que puede desplegar. Entonces, desde los inicios griegos la filosofía sabe que ignora. Ustedes deben recordar la anécdota del oráculo que está en la Apología de Sócrates, de Platón. Allí, Sócrates dice que un amigo suyo, Querefonte, fue a preguntarle al oráculo si había en Atenas alguien más sabio que Sócrates. El oráculo contesta que no. Sócrates se muestra perplejo: sostiene que si por un lado el oráculo no puede mentir, por otro no está claro lo que quiere decir, ya que no se considera portador de cualquier saber digno de tal juicio. En todo caso, Sócrates decide emprender una búsqueda que dé algún sentido a lo dicho por el oráculo. En ese gesto comienza la tarea no solo de un filósofo, sino de un profesor de filosofía. Lo que Sócrates emprende es una búsqueda de sentido, y el modo de realizarla es la interrogación de sí y de los otros. Más allá del carácter ficcional de la anécdota, ella muestra algo interesante: Sócrates no es un profesor de filosofía que va a enseñar a los otros algo que no saben; en verdad es la propia búsqueda que da forma a una práctica que hace de Sócrates -y cuando sus encuentros son más interesantes, también de los otros- algo que no era al inicio.

Sócrates se encuentra con distintos interlocutores. Primero, los políticos luego los poetas y finalmente los trabajadores manuales ${ }^{2}$ En todo caso, Sócrates deja ver una cierta actitud irreverente, no solo por el contenido de la sentencia oracular, sino por la actitud con la que emprende la búsqueda de ese saber: en efecto, comienza por un hombre de los que tienen más fama de sabio, para "en cierto modo, confutar al oráculo". De modo que Sócrates, aún frente al oráculo, marca una de las dimensiones principales de su práctica filosófica: confutar los dichos que no pueden ser aceptados tal como son enunciados.

El primer interlocutor es un político que parece sabio para los otros y, sobre todo, para sí mismo; pero no lo es, según concluye Sócrates después de dialogar con él. Y afirma que, al intentar demostrarle que no lo es, se gana su odio y el de los presentes. Por eso, dice Sócrates:

Es probable que ninguno de nosotros sepa algo de valor, pero éste cree saber y no sabe, en cambio yo, en tanto, efectivamente, no sé, tampoco creo [saber]. Parece, pues, que soy más sabio que éste en esta misma pequeñez: que lo que no sé tampoco creo saber ${ }^{3}$

\footnotetext{
${ }^{2}$ PLATON. Apología de Sócrates. 21b-e; 21e-22c; y, 22c-e.

3 Ibíd. 21d.
} 
Lo que diferencia a Sócrates del político examinado es una negatividad: no creer saber. A continuación sigue interrogando a más políticos y el resultado es siempre el mismo. Cuanto más reputados, menos dotados, en cuanto que los menos favorecidos están más cerca de ser sensatos.

Después llega el turno de los poetas, quienes no pueden dar cuenta de sus propias obras. Sus obras no se deben a su saber, sino a dotes naturales e inspiración. Dicen muchas cosas bonitas, pero sin saber por qué las dicen. Como poetas creen ser los más sabios de todos, pero no lo son, por lo que Sócrates cree ser más sabio que ellos.

Finalmente, es el turno de los trabajadores manuales. A medida que Sócrates va descendiendo en la escala social, los saberes que encuentra se muestran más sólidos. A diferencia de los anteriores, los trabajadores manuales saben algo que Sócrates realmente no sabe. Pero su problema es que quieren aplicar ese saber a las cosas más importantes y allí lo estropean, no reconociendo los límites. Así, Sócrates también considera preferible su relación con el saber que la relación con el saber y la ignorancia que mantienen los trabajadores manuales.

De este modo, la investigación emprendida por Sócrates confirma al oráculo: él es, efectivamente, el ateniense más sabio, porque es el único que sabe de su propia ignorancia. Sócrates interpreta el oráculo así: al decir que él es el más sabio, lo señala como un ejemplo, modelo o paradigma de que, entre los seres humanos, el más sabio es aquel que, como Sócrates, reconoce que nadie es sabio verdaderamente en relación con el saber.

Pensemos específicamente en la enseñanza de la filosofía. Sócrates ha enfrentado tres rivales, contendientes que son así mismo posibilidades del profesor de filosofía. Están en la escuela y también fuera de ella. Pero, y tal vez este aspecto sea aún más interesante, también son tres posibilidades de dentro, del camino que el propio profesor de filosofía puede estar tentado a seguir. La política es la posibilidad de ver en la enseñanza de la filosofía una proyección social concreta y acabada, una productividad comprometida con la transformación del estado de cosas; es la extensión de un sentido, utilidad o producto tangible en sociedades plagadas de injusticias como las nuestras; así, la política es el doble de la filosofía en la polis. La poesía es la propia dimensión estética de la filosofía, la que la aproxima más específicamente al arte, al desinterés y lo sublime; es la consumación de la palabra en la propia palabra; por eso, la poesía es el doble de la filosofía en el lenguaje. Finalmente, la técnica es la seducción de un método que torne a la filosofía productiva, eficaz, desde la propia didáctica, hasta una finalidad dictada por el mercado, la ciencia o desde cualquier otro marco externo; es el predominio de un orden que pretende regularse a sí mismo y, en particular, al propio pensamiento; la técnica es el doble instrumental de la filosofía. 
Sócrates enfrenta esos embates externos y tentaciones internas para afirmar un lugar desde donde problematizar los saberes con los que se encuentra la filosofía. El lugar que define es, significativamente, el de una relación con el saber y su doble, la ignorancia. Sócrates no concibe la filosofía como un saber, sino como una relación con el saber a partir de la cual una serie de prácticas pueden desarrollarse. La filosofía es, para Sócrates, algo así como una condición para poder desplegar cierto camino en el saber.

Ese mito de la ignorancia de Sócrates es también el mito de la filosofía y de quienes la enseñan, en tanto asimila su modo de vida al de "todos los que filosofan" "El "todos" es interesante porque revela que, a pesar de considerarse el más sabio, Sócrates está lejos de considerarse el único en hacer lo que hace. También lo es el uso del participio, un adjetivo verbal, en la medida en que concibe el filosofar como una posibilidad de una acción en ejercicio. La filosofía no nace como un saber, sino como una forma de ejercer, prácticamente, cierta relación con el saber.

El legado de este mito para la filosofía no es menor. Sócrates la hace nacer de un saber divino -contra el que después se vuelve- y, a la vez, no le da el suelo firme de un saber de certeza, sino que, sobre todo, la asocia a una relación con el saber o, mejor aún, con el contrario del saber, la ignorancia. Vivir filosofando significa, para Sócrates, dar un cierto lugar que destaca a la ignorancia, en el pensamiento y en la vida, tener una relación de potencia, afirmativa y generativa con la ignorancia. El problema, según Sócrates, no estaría en ser ignorante. De hecho todos los seres humanos lo somos. La cuestión principal pasa por la relación que tenemos con la ignorancia. Algunos la niegan, la ignoran. Ese es el principal defecto de un ser humano, parece querer decir Sócrates: ignorar su ignorancia. Todo se puede ignorar, menos justamente la ignorancia. Después de sus conversaciones con políticos, poetas y trabajadores manuales, tal como son narradas en la Apología, Sócrates concluye que es el único en Atenas que sabe de su ignorancia, que ignora todas las otras cosas, menos la propia ignorancia. Eso lo torna el más sabio. El problema principal de los que ignoran la ignorancia es que se fijan a una relación disfrazada con el saber y a partir de esa relación se cierran a poder saber lo que de hecho ignoran. Clausuran toda búsqueda. Como si fuera poco, cuando alguien les muestra sus fragilidades, reaccionan violentamente, como lo hacen contra Sócrates

El mito de su saber de ignorancia otorga una tremenda fuerza a la vida de Sócrates y al pensamiento en general. En principio, la ignorancia es un vacío, una falta, un defecto ( $i$ gnorantia). La sabiduría parece ser su contrario, una presencia, una plenitud, una virtud. Sócrates, al postular que su saber radica en una cierta relación con la ignorancia, da vuelta a las cosas, invierte el sentido común. Nada más vacío que un ser humano que se considera sabio. Nada más impotente que los presuntos sabios. Nada más potente y afirmativo que un ser humano que se sabe ignorante. El gesto de Sócrates es impresionante: nada es lo que

\footnotetext{
${ }^{4}$ Ibíd, 23d.
} 
parece. Al contrario, las cosas son opuestas a cómo parecen: la ignorancia sabe, el saber ignora; el ignorante sabe, el sabio ignora. Tamaño sacrilegio. La ignorancia no es lo que parece, sólo una negatividad puede ser todo lo contrario, la afirmación que torna posible el saber, el pensamiento, en fin, una vida digna para los seres humanos. Así nace la filosofía y su enseñanza: mostrando que las cosas no son lo que parecen.

De paso, como la ignorancia, la infancia también es una palabra construida sobre un prefijo de ausencia y que suele ser visto como una debilidad. En este caso sería la ausencia de palabra. Pero, como la ignorancia, también pueden ser una fuerza, una potencia. La infancia es lo que nos permite también estar vivos; el momento de aprender a hablar, de querer hablar algo que no se habla. Sin infancia no aprenderíamos a hablar; o estaríamos hablando siempre lo mismo, así como sin ignorancia estamos quietos pensando que ya sabemos lo que es preciso saber. Si estamos aquí para aprender a hablar y para encontrar otras palabras es que tenemos todavía un resto de infancia, que le hacemos un poco de lugar. La infancia tiene que ver con aprender y con transformar lo que somos o con encontrar.

Recuerdo una historia de un mexicano, el Subcomandante Marcos, del EZLN, que se llama "La historia de la búsqueda", que dice que los seres humanos nacemos con pendencias y que vivir tiene un poco que ver con encontrarse uno mismo. En ese texto, que remite a un saber tradicional indígena, uno se encuentra uno mismo a través de los otros. Es una historia que sirve como metáfora para la vida de un profesor y para pensar la relación entre buscar y encontrar. Solemos pensar que si alguien encuentra algo es porque lo ha buscado, pero puede ser más compleja la cosa; puede ser que encontremos muchas veces lo que no buscamos, y puede ser también que valga la pena buscar más allá del encuentro exterior que genera esa búsqueda.

Habíamos hablado de Deleuze, después de Sócrates, ahora del Subcomandante Marcos. ¿Qué relación guarda la filosofía con la tierra? ¿Qué mapas traza en el pensamiento? Bueno, la filosofía está usualmente relacionada a una tradición que comienza con los griegos y no está mal, pero tenemos que pensar, que una filosofía poco sirve si no nos ayuda a pensar el propio error o la propia tierra o a pensar los propios problemas. Pues la relación de la filosofía con la tierra es muy importante. Y nosotros que vivimos en una tierra que está marcada por la injusticia, por el dolor, por la resistencia, creo que podemos hacer de la filosofía un campo, un testimonio, en el pensamiento, de lucha contra la injusticia, de lucha a favor de la resistencia, contra el olvido. En ese sentido América Latina no es necesariamente una tierra geográfica en el sentido de un conjunto de países o de una población; es más bien el nombre de una condición, de una manera de habitar el pensamiento. En ese sentido se puede ser latinoamericano habiendo nacido en Europa o se puede ser europeo habiendo nacido en América Latina. La condición en la que se ejerce el pensamiento no tiene que ver con lo que dice el documento o la cédula de identidad, sino con una cierta manera de habitar el pensamiento y darle sentido a su ejercicio, es decir, con preguntarse y ayudar a los otros a preguntarse para qué hacemos lo que hacemos, para qué enseñamos lo que enseñamos, si para reproducir o para resistir, para legitimar o para 
transformar, para olvidar o para recordar. Estoy planteando las cosas un poco drástica y esquemáticamente para provocarlos. Sé que todo es un poco más complejo.

\section{La inquietud filosófica: un encuentro de experiencias}

Una es la palabra experiencia: encuentro de experiencias. Recuerdo un filósofo francés contemporáneo, Michel Foucault ${ }^{5}$, que en muchos sentidos uno podría decir que es un filósofo latinoamericano, en el contexto que acabo de mencionar, el de alguien que pone el pensamiento a favor de la resistencia y contra la injusticia. Él opone experiencia y verdad de una manera que puede ayudarnos a notar con más intensidad el valor y el sentido de un encuentro de filosofía. Foucault diferencia dos posibilidades de la escritura (y podríamos decir del pensamiento, de la educación, también): un ejercicio que legitima lo que ya existe -a eso llama verdad- y uno que transforma lo que somos.

Foucault se refería a los libros, decía que hay dos tipos de libros: se escribe un libro desde la lógica de la verdad cuando uno piensa que sabe o que ha descubierto algo, y entonces el sentido de la escritura es transmitir lo que ya se sabe; Foucault afirma que es el caso de la mayoría de los libros que son escritos; mucha gente puede creer que sabe algunas cosas y escribe libros para transmitir lo que sabe, las verdades en las que está instalado; así como hay escritores de libros-verdad, hay también lectores de libros-verdad: gente que lee libros porque piensa que encuentra en esos libros verdades que no conoce, que no sabe; piensa que se va a enterar de saberes que ignoraba; la lógica de la verdad es la lógica de la transmisión o incorporación; Foucault agrega que jamás habría tenido coraje de escribir libros de ese tipo, y los diferencia de los libros-experiencia, libros que también transmiten verdades, pero el sentido de la afirmación de esas verdades no es la transmisión, sino justamente provocar un cuestionamiento de la relación que tenemos con la verdad de lo que se escribe.

Si cuando escribimos desde la lógica de la verdad lo hacemos para transmitir verdades, cuando escribimos desde la experiencia afirmamos verdades, pero no para transmitirlas, sino no para problematizar la verdad en la que estamos instalados. Si la lógica de la verdad es la lógica de la trasmisión, la lógica de la experiencia es la lógica de poner en cuestión la relación con la verdad. Así como hay escritores de libros-experiencia también hay lectoresexperiencia, o sea, quienes leen un libro para transformar la relación que tienen con el tema en cuestión. Podrán saber también nuevas verdades, claro, pero ese no es el sentido principal que anima la lectura.

No se trata de defender una forma y condenar la otra. Algo así como "viva la experiencia" y "muera la verdad". Nada de eso. Se trata de pensar el sentido por el que escribimos lo que escribimos o leemos lo que leemos. El punto es que esta distinción es bastante fértil y puede considerarse con otras cuestiones. Por ejemplo, la propia filosofía: podemos

5. FOUCAULT, M. El yo minimalista y otras conversaciones. Buenos Aires: La Marca, 2003. 
encontrarnos con la filosofía desde la lógica de la verdad o desde la lógica de la experiencia. Repito, no se trata de decir lo que está bien y lo que está mal. Mucha gente se encuentra con la filosofía para aprender sus verdades, y no está mal, sirve para muchas cosas, y quienes enseñan filosofía desde la lógica de la verdad transmiten verdades que piensan que los otros no saben y tienen que tener. Pero la filosofía puede abrirse a una relación de experiencia, es decir, podemos, a través de la filosofía, encontrar verdades que nos ayuden a transformar la relación que tenemos con lo que pensamos, con lo que sabemos, y que eso le pase también a otros, que la oportunidad de encontrar la filosofía sea una posibilidad de transformarse y no apenas de incorporar lo que no se sabe.

Entonces, la experiencia y la verdad son también posibilidades en la educación de entender el enseñar y el aprender, es decir, hay muchos maestros, profesores, docentes en general, que están inspirados más por la lógica de la verdad que por la lógica de la experiencia, que entran a un salón de clases porque piensan que ellos tienen verdades que los alumnos no tienen, y el sentido principal de su acto educativo es transmitir esas verdades. Claro que eso se asienta en relaciones de poder; un docente puede transmitir esa verdad porque está situado en un lugar de poder que le permite transmitir eso como si fuera justamente verdad, y la posición del alumno en general es la posición de incorporar esa verdad, aceptarla o recibirla; pero también el salón de clases puede estar regido por la lógica de la experiencia, es decir, podemos pensar que entramos a un salón de clases y, por lo tanto, transmitiremos y recibiremos verdades, pero el sentido principal de nuestra presencia allí no estará ni en el dar ni en el recibir verdades, sino en poner esas verdades al servicio de la transformación de lo que pensamos y de lo que sabemos, es decir, podemos hacer del encuentro pedagógico en una sala de aula una experiencia, podemos entrar a una sala de aula no tanto para transmitir lo que sabemos, sino para problematizar lo que sabemos, lo que pensamos y, por ende, lo que somos.

Bueno, repito, no se trata de condenar una lógica y consagrar la otra, pero sí de apreciar dos sentidos opuestos de la tarea educadora en esta dicotomía un poco simplista y grosera que les estoy presentando. Y claro que las dos lógicas podrían complementarse, además de oponerse.

El punto es que este encuentro de profesores que dicen que enseñan filosofía puede dar lugar, espero, a experiencias que nos permitan plantearnos preguntas como las que les he sugerido: ¿qué es la filosofía?, ¿qué es enseñar?, ¿qué relación hay entre enseñar y aprender (filosofía)? Podríamos enfrentar estas preguntas desde la lógica de la verdad y decir por ejemplo: "La filosofía es, como dice Hegel..." o "Enseñar filosofía significa necesariamente...", pero parece que la inspiración de este encuentro tiene más bien que ver con la experiencia. En ese sentido, auguro movimientos, traslaciones, desplazamientos, viajes. Espero que salgamos del lugar en el que estamos cómodamente instalados para ocupar otro lugar en el pensamiento, para encontrarnos con lo que no pensamos. 
Espero que estemos entonces dispuestos a hacerle lugar a lo que parecía impensable, a lo que parecía inútil, desnecesario o inconveniente de ser pensado; cuando nos relacionamos con la filosofía desde la lógica de la experiencia, es como si se abriese un nuevo mundo a ser habitado en el pensamiento, que nos exige salir de ese mundo en el que estamos cómodos y nos propone la incomodidad de un mundo que no sabemos, que no conocemos, pero que el encuentro con el otro y los otros pueden propiciar.

Entonces es también con esa inspiración que vinimos, con esa inspiración de la experiencia, de la gratitud y de la invitación generosa, acogedora y sin condiciones, la condición de la hospitalidad que no pregunta, que acoge, digamos, sin poner condiciones, como diría J. Derrida $^{6}$ sin decir a qué tiene que venir, sino invitándote a traer lo quieres traer y, en ese sentido, nos disponemos a explorar los caminos de la experiencia.

Les recuerdo, un breve episodio de un diálogo de Platón, que se llama Laques, diálogo que tiene que ver, como tantos otros, con la educación. Lisímaco y Melesias han recibido, como también Alcibíades, una educación negligente. Sus padres, Arístides y Tucídides, han sido eminentes hombres públicos, de la política externa e interna de Atenas, de la guerra y de la paz, pero se despreocuparon completamente del cuidado de sus hijos. Al contrario, Lisímaco y Melesias, fruto de esa educación, no tienen una vida de la que enorgullecerse y no quieren repetir, con sus hijos, que llevan sus mismos nombres, lo que sus padres han hecho con ellos. De modo que consultan a dos afamados ciudadanos, Laques y Nicias, sobre los saberes que es necesario impartir a los jóvenes. El diálogo surge entonces porque los atenienses reciben una educación deficitaria. La crisis de la educación tiene ya muchos siglos, no es un problema exclusivo de nosotros.

El punto es que, como siempre, delante de Sócrates, sus interlocutores no se salen muy bien y no consiguen dirimir la cuestión que los convoca. Sócrates afirma que es porque ninguno es experto en educación: "Hay que buscar a un artista en el cuidado del alma". 7 Y da dos criterios para saber si se es o no experto en este arte: por los buenos maestros que alguien ha tenido o por las obras que ha sido capaz de realizar, esto es, las almas excelentes que ha conseguido generar.

Sócrates se declara a sí mismo desprovisto de ese arte, en la medida en que no ha tenido ningún maestro ni recursos para pagar un sofista. Y aunque el tema lo apasiona desde pequeño, todavía no ha descubierto el arte de educar ni ha generado saber alguno sobre él. Por eso pide a los expertos Nicias y Laques que retomen la palabra y muestren sus credenciales en el arte de educar.

Como en otras ocasiones, Sócrates se pone del lado del no saber, para escuchar a los que supuestamente saben sobre el asunto. Es interesante la manera en que Nicias acepta el

\footnotetext{
${ }^{6}$ J. DERRIDA, J. La hospitalidad. Buenos Aires: La Flor, 2000

${ }^{7}$ PLATON. Lacques. $185 \mathrm{e}$.
} 
desafío, sabiendo la que se le viene: “dar, de sí mismo, razón, de cómo es su modo de vivir actual y por qué ha vivido la vida que ha llevado"8. Nicias sabe que, frente a Sócrates, diríamos frente al filósofo o al profesor de filosofía, hay que justificar, dar razón de la propia vida, la pasada y la presente. Nicias recuerda incluso un dicho de Solón sobre lo valioso de aprender mientras se está vivo. Pero lo más interesante viene cuando remata su intervención:

Pues estar sometido a la piedra de toque de Sócrates no es nada desacostumbrado ni siquiera desagradable para mí, sino que prácticamente desde hace bastante tiempo he sabido algo: que cuando Sócrates está presente, nuestro discurso no podría ser sobre los jóvenes, sino sobre nosotros mismos. ${ }^{9}$

La intervención de Nicias es especialmente significativa por el valor y el sentido que da a la presencia de Sócrates, al encuentro con un filósofo o profesor de filosofía: el de una piedra de toque; alguien que pone a prueba, como Sócrates mismo se presenta en la Apología; y lo que un profesor de filosofía pone a prueba es un modo de vida, la forma que alguien le da a su propia vida. Eso es lo que siempre va a estar en juego: nosotros mismos y la manera en que vivimos.

De lo que se trata, al encontrarse con un profesor de filosofía, no es hablar de cosas externas a nosotros, sino de por qué vivimos la vida que vivimos y no otra vida; ese encuentro nos hace en el fondo problematizar por qué elegimos el tipo de vida que elegimos para vivir. Este examen suele generar incomodidad, porque es más fácil vivir una vida tranquila, es más fácil vivir sin problematizar la propia vida, pero es también la condición y la posibilidad de vivir de otra manera, es también la posibilidad y la condición para poder tener nosotros una vida diferente de la que tenemos; espero que este Encuentro de profesores que dicen enseñar filosofía propicie ese movimiento que, en última instancia, es la posibilidad de poner en cuestión una vida que, al menos en esta parte del mundo, no parece digna de ser vivida para la inmensa mayoría de las personas.

Tunja, 2 de septiembre de 2008

\footnotetext{
8 Ibíd, , 187e-188a

${ }^{9}$ Ibíd, 188b-c.
} 